\title{
Governance and Power-Sharing in TVET in Nepal: Sharing of Practical Experiences
}

\author{
Erik Winther-Schmidt*, and Rajendra Bahadur Shrestha \\ Dakchyata: TVET Practical Partnership Programme, Kathmandu, Nepal
}

\begin{abstract}
Addressing the overall theme of Governance and Power-Sharing in TVET in Nepal, the paper starts by defining the key concepts. Governance surely means involvement of Government, but Government can be extended by involving civil-society actors, like the private sector, which can also play an important role in executing some roles and responsibilities. When such non-government sectors are involved in the planning, execution and financing of TVET, this is where we speak of powersharing. To be effective, power over TEVT must be executed at many levels: at a macro level (federal level), at a meso level (provincial level), and at a micro or local level. One powerful way of ensuring this power-sharing between government and non-government in TVET is through public-private partnerships (PPP). It is argued that employers- for many good reasons- have so far not been playing their optimal role in TVET. This should change and it is argued how PPP can ensure this change. The outcome would be the bringing about of more market-relevant and demanddriven qualifications and skills that the employers say they need to staff their businesses and industries. With the point of departure in mind that GoN is presently not at the verge of reforming its overall TVET system, this is the time now where important lessons can be gathered and learned from, which can give a direction to new policy initiatives.
\end{abstract}

Keywords: Governance and power-sharing in TVET, public-private partnerships, training and development, federalisation, multi-level governance

* Corresponding Author.

(7) $\underline{\text { erikwshome@gmail.com }}$
ISSN: 2091-0118 (Print) / 2091-2560 (Online)

(C) 2020 The Author(s).

Journal homepages: ${ }^{1}$ http://www.kusoed.edu.np/journal/index.php/je

${ }^{2}$ https://www.nepjol.info/index.php/JER/index 


\section{Clarifying Some Key Concepts}

Governance and power-sharing: Let us start by clarifying how we understand the subject of this paper, i.e. Governance and power-sharing in TVET? Indeed, governance is fundamentally about power, relationships and accountability. In the static mode, we map out who has influence, who makes decisions, and how those who have influence and make decisions are held accountable. But in a dynamic sense, we can understand governance as the activity of governance, the process whereby elements in society wield power and authority, influencing and creating policies and decisions that affect public life. In this definition, governance emphasizes interaction among institutions, processes, traditions and cultures. It determines how power is exercised, how decisions are taken, and how stakeholders, including citizens, have their say. So while governance often takes its starting point in government, it does not end there (Global Development Research Center [GDRC], n.d.; Tamayao, 2014). With governance, we do mean government, but not only; governance in our use include civil-society actors, meaning that governance includes three sectors: the public sector (state actors and institutions), the private sector (households and companies) and civil society (nongovernmental organisations). They all play a role in governance. In a democratic country like Nepal, these three sectors are said to work hand-in-hand in the execution of governance. This widening of the concept of governance is based on the realisation that the government cannot and should not do everything for its people in order to fulfil all needs of society. The government should not only rely on itself but should also involve other sectors of society, by sharing power with these other sectors, drawing on their expertise and insights, thereby improving governance. However, there are many things that the non-governmental organizations and private sector cannot do- developing policies and standards etc. Therefore, power-sharing in our context means to share the responsibility for decision-making and political action, in short: Multilevel participation.

Multilevel governance and partnerships: When the government is not alone in exercising governance but draws in other domains (or sectors) from top to bottom of society, we talk about multilevel governance. The specific aim of multilevel governance is to produce coordinated action, building on synergies between the different tiers of government, and ensuring the engagement of other public and private 


\section{2 | E. Winther-Schmidt \& R. B. Shrestha}

stakeholders. Multilevel governance represents a political culture or behaviour, rather than a legal instrument, and cannot be seen solely through the lens of the division of powers. This means that effective policy development and implementation is firmly based on an active partnership which is supported by systemic and meaningful horizontal and vertical coordination mechanisms. In Nepal, the private sector has no clearly defined role in the TVET policy, but the private sector is still part of the TVET equation. So multilevel governance is de facto exercised through a string continuous process of negotiations and implementation but done without assigning exclusive policy competence of political authority to any one of these levels, i.e. de jure. Even if not lawbased, these practices are still an important part of reality. This last point is noteworthy. If relationships are to be formed without exclusive policy competence, in short: not bound by laws or regulations, there must be other mechanisms in play to underpin such relationships - and there is. In a democracy, where governance is not only executed by the government, but where governance rests on wider domains of society as mentioned in the above, collaboration and participation is not achieved by dictate, but attained on a voluntary basis, based on custom, tradition and practice. This mechanism of interaction could be through the formation of partnerships, where partners work together in a voluntarily based, yet committed relationship, in which they supplement one another, to achieve a set of goals, even to govern. Partnerships are entered into every day, not only between businesses but also between business and government. We shall revert to and explain very soon to why public-private partnerships (PPP) are of special interest in any discussion on TVET since it touches upon the very nature and social role of TVET.

Partnerships in TVET: Why are public-private partnerships (PPP) important in a discussion on TVET? PPP as a way forward does not only underpin democratic principles like participation and rule of law and other high standards of ethics, but also refer to practical standards of effectiveness and efficiency. Multilevel governance, i.e. widening participation by drawing in other sectors into governance has become a necessity because of the always evolving complexity and ever-growing needs of a modern, dynamic society, which government alone cannot monitor, control and steer efficiently and effectively. To achieve that efficiency in governance, the different actors must work together and share the responsibility to meet the needs of society. This

Journal of Education and Research, Vol. 10, No. 1, 2020 
widening through practical partnership modalities is particularly interesting in the case of TVET, due to TVETs specific roles and functions in society. In TVET, in the technical education and training that students go through, either to get a job or to become more competent in a job they are already having (e.g. through up-skilling) or establishing their own enterprises, the world of schooling and the world of work meet, which is one of the very unique features of TVET. For this reason, TVET and skills development has been characterized as a "bridge" between the world of education and training and the world of work and lifelong learning. TVET cuts across every sector of the economy and relies on effective dialogue and interaction between education and training providers, labour market stakeholders including employers, worker representatives, training providers and other stakeholders. For these reasons, TVET is expected to contribute towards a wide range of (sometimes contradictory) socioeconomic goals, including full employment, increased productivity and competitiveness, social cohesion, equity and sustainability (European Training Foundation [ETF], 2013; UNESCO/ILO, 2018). With this important role in society, we should expect a fight over influence in TVET - everybody wants to take part in TVET governance! Of course, there are common interests in TVET. Government overall, as well as TVET students and employers, will appreciate that education and skills learned in schools are as relevant and as easily applicable in the workplace as possible and we should, therefore, expect employers to want to have a big say in TVET. Even so, in reality, this interest may not always be outspoken. In a modern state, basic education (and primary health) as "public good" often falls under the realm of government and the world of work and lifelong learning under the private sector and no "universal rule" exists on how the two shall best share power, responsibilities and execute decisions. In some countries, TVET as a sector is much closer to the private sector than is the case in Nepal, where the private sector traditionally plays a rather withdrawn role in TVET. We shall revert to this sad fact time and again in this paper.

Governance, power-sharing and change: Compared to 20-30 years back, the keywords in TVET have changed a lot. At a time where developing countries often lacked the physical facilities to provide high numbers of TVET students with technical qualifications and skills, the challenge was to build institutions that could deliver these 


\section{4 | E. Winther-Schmidt \& R. B. Shrestha}

skills. Since such institutions need lots of equipment and highly specialized teachers to operate them, they were often without reach for developing countries, for simple economic reasons. Even so, it became obvious, through increased industrialization and economic activity that all types of craftsmen were in dire need, for which reason market research to determine skills demand in the market was not really needed. All with TVET training would be able to land a job. This approach has changed fundamentally over time, not least because of a situation, where young people with glossy and eyecatching TVET certificates often realized that the demand for their skills was not there. The weak spot in the above approach was that TVET students only received training within those areas that the training institution could deliver. In today's jargon, we say that the effort to train them is "supply-driven", driven by what the school can offer, not what the market wants and needs. To reverse this and to get this "demand-drive" into the equation, TVET should be in a position to offer qualifications and skills in what the employers and the market deemed needed. From then on and through a gradual process that has caught increasing momentum over the last 10-15 years, buzzwords like relevance, quality, participation, ownership (not by government, but by employers and social partners) have caught on. This naturally brought forward the question of how to ensure this, how to ensure that the rules of the market, the demand-and-supply mechanism, enters into TVET. The answer was located in finding ways to increase stakeholder participation in TVET development. The theory or the thinking is that in order to ensure that young people - through TVET - are provided qualification and skills that are actually in demand is to involve as far as possible - the end-users in the market relation: the employers. There are of course many ways to do this, and many TVET development projects around the world each hone in on one or two strategies to achieve that, all with this in common: that greater involvement of employers in arranging for all or most aspects of TVET will lead to the provision of more relevant and market-responsive training. In other words, it should produce a system that is better able to match the "supply" of training delivered by the training market (incorporating both public and private providers) to the "demand" created within the labour market. In this new approach, Ministry of Education or Ministry of Labour were found not to be ideally suited for that assignment and multilevel governance was identified as a solution 
and this called for a change in ways that TVET is governed and managed. Widening governance through dialogue and partnerships as a means of managing TVET systems through proactive involvement of the private sector was seen as an alternative to purely centralized government control. This is not done with a strike of a pen. The realisation is not enough, even if it is an important first step. Change has to be followed up by finding new ways to nurture the multi-stakeholder dialogues and partnerships required to deliver more effective and responsive TVET provision in the context of today's complex and rapidly changing labour markets. Therefore, when we address the issue in this paper of governance and power-sharing in TVET, we want to address the issue of renewal and change, looking for a new balance for government and private sector in sharing responsibility and sharing power in TVET. And further: to reach this new balance, we shall be arguing that the mechanism of establishing and running publicprivate partnerships in TVET seems to be a particularly promising way forward, in the case of Nepal.

In summing up: Strengths of PPP. Allow us to sum up this clarification of fundamental concepts by making a point on why we favour PPP (as contrasted with the government directive, instruction, demand or even dictate in TVET). Firstly, partners who can bring different strengths to an agreement can do so through forming partnerships voluntarily. Secondly, even if TVET is not a commodity like bananas and rice, it does represent a service on offer to be bought and sold, and as such we believe TVET will gain from being tested under some kind of market condition, where buyers and sellers of the service meet and exchange. Rather than TVET just being supplied, PPP offers a modality for buyers and sellers to meet and enter into a relationship that is mutually beneficial and PPP is an obvious way to introduce the demand-aspect into TVET. Thirdly, this ensures that the service is considered beneficial by all sides: employers have access to employees who can do the job and upkeep production in the most efficient and effective ways, employees earn wages to improve their livelihood and government (through general taxation revenue) can finance its expenditure that comes with governance. Fourthly and finally, this broad societal acknowledgement for TVET that follows underscores the point that deep and durable change in TVET does not happen only because a country leader sees how matters are done elsewhere. While lessons learned from elsewhere could surely inspire, lasting change rests on $a$ 
$106 \mid$ E. Winther-Schmidt \& R. B. Shrestha

multilevel, broad cross-social country dialogue and broad-based buy-in by stakeholders. In the following, we shall argue that our experiences with PPP may have some important lessons to offer in this respect.

\section{Who We Are}

The two authors of this paper both work in a Project, which has the formation of PPP in TVET in Nepal as its main and overarching goal. The Dakchyata TVET Practical Partnership Project ${ }^{1}$, funded by the EU but managed by British Council, was established in 2017 and runs until 2021, is a skills development project, the purpose of which is to pilot ways to improve relevance, quality and sustainability of training provision in TVET by trying out different PPP models across three economic sectors in Nepal: Agriculture, Tourism and Construction. Besides of Government, Dakchyata works with industry associations, confederations, chambers of commerce, small businesses, professional federations, commodity associations, polytechnic schools, technical training providers, employer associations, and others, to carry out two main activities: 1) to improve TVET provisions through awarding grants to establish PPP approaches in TVET with the aim of generating learning on enhancing the relevance, quality and sustainability of TVET provision in Nepal and 2) provide technical assistance to the Government of Nepal and the national TVET authority (CTEVT) to strengthen governance, coordination and reform of the national TVET system, and raise the profile of TVET in Nepal. We believe that this work has given us some insights and experiences that - when shared here - can deepen the understanding of, not only which challenges the TVET sector in Nepal are presently facing, but also how some of these can be overcome. We shall neither claim nor attempt to try to cover all aspects of TVET and TVET challenges concerning governance and power-sharing in this Paper. But we do believe that renewal and change in status quo is called for in Nepal and we want to focus on and highlight the possible changes that the PPP modality has to offer when applied in governance and power-sharing in TVET. ${ }^{2}$

\section{Problems and Possible Solutions}

No TVET system anywhere in the world is perfect. TVET always has to adapt to ever-changing ways of production, new technology, new standards and innovation or 
new ways of organizing the workforce. But the speed with which TVET adapts and the way that main actors relate to making this happen is very different, worldwide. The type, size and composition of production has not favoured the development of largescale industry in Nepal, where government and employers naturally came together to form and operate a TVET system in a partnership spirit, because of urgent market demand. As mentioned in the above, donors assisted GoN in meeting the needs of TVET institutions, while the mechanisms to capture demand-side needs were not well developed. Perhaps due to this void, Government pushed forward and took charge of TVET institutions (e.g. CTEVT) and employers held back, and some mutual suspicion is easily detected in the present-day relationship between government and the private sector. According to research carried out by Dakchyata, the two sides: Government and employers, do accuse each other for not giving and taking sufficient space for collaboration in TVET (Ho, 2018). While Government maintain that representation for private sector is built into many TVET decision-making bodies of importance, but employers all the same show little interest, employers oppositely maintain that this influence is mostly symbolic and Government is not ready to step aside and let others decide. This situation is not at all conducive since governance and the law should oppositely aim for reinforcing interaction between stakeholders and improve accountability, transparency, coherence, efficiency and effectiveness of the policy. The existing policy on TVET from 2012 does not mention this cross-sectoral collaboration and no new act is presently planned, so this problem may persist for some time (Ministry of Education, Science and Technology, 2019). ${ }^{3}$ So until that day comes, we may have to settle for less and here is where the partnership modality comes in, perhaps as an interim solution, perhaps as a much more permanent so. PPP can be one of the ways to strengthen multilevel governance, where government and private sector in a spirit of sharing power work together in TVET.

\section{What We Set Out to Do}

Creating multilevel governance processes is, therefore, a challenge, particularly in countries like Nepal, where governance of TVET has traditionally been rather centralized. Groundbreaking new laws rarely come unexpectedly and successful laws 


\section{$108 \mid$ E. Winther-Schmidt \& R. B. Shrestha}

are those that are anticipated and well prepared for. Therefore, we think that the best way in seeking renewal on issues of governance and power-sharing in TVET in Nepal right now - in the given circumstances - is to facilitate a PPP dialogue on two dimensions simultaneously: horizontally and vertically. Renewal must come from a shift towards more participatory, multilevel governance approaches, obtained through the involvement of a broad range of stakeholders, on many different levels of society, where the public and the private sectors start collaborating in TVET on something practical and doable, in win-win situations where all have something to gain. To maximize the synergic effects, this collaboration should take place simultaneously on national, provincial and local levels. People need to see another reality, something that works, something to copy and to learn from. The public and the private sectors need to enter into relationships or even partnerships, to stimulate the dialogue at national, provincial and local levels about how TVET can become that flexible tool that can unlock the mismatch between demand and supply of skills and qualifications (Asian Development Bank, 2016; Bajracharya, 20194). All stakeholders need to experience another reality. Even only in a patchy way, this is what Dakchyata sets out to do and we wish to share some of these experiences in this paper.

\section{Our Methodology}

The way which we will go about the above is like this: As argued in the above, i.e. considering that the multilevel governance and power-sharing is presently not adequately institutionalized and law-based in TVET in present-day Nepal, we intend to describe and demonstrate some ways, through which the Dakchyata Project is presently carrying out activities, which are preempting or anticipating such a state of multilevel governance and power-sharing, on an exemplary level. We will be doing this by describing some of the PPP activities, which the Dakchyata project is presently preparing for or actually implementing. (In other words, we are not ourselves gathering new data for this paper, only organizing and presenting existing data, so that they fit the purpose here, which is to demonstrate how these various forms of PPP can contribute to the process of developing multilevel governance and power-sharing in TVET in Nepal). 
Governance and Power-Sharing in TVET in Nepal | 109

In an exemplary form, we shall demonstrate this through the presentation of $\mathbf{4}$ different cases, derived from 3 different societal levels, i.e. at macro, meso and micro levels.

Table 1

Types of Experiences Across Levels

\begin{tabular}{ll}
\hline Societal Level (3) & Type of Experience (4 Cases) \\
\hline 1. Macro/Federal Level & $\begin{array}{l}\text { Case 1: TVET PPP Working Group } \\
\text { Case 2: Grant to National Employer Organisations }\end{array}$ \\
2. Meso/Provincial Level & $\begin{array}{l}\text { Case 3: Grant support to Provincial Level CTEVT } \\
\text { Schools }\end{array}$ \\
Case 4: Grant to form PPP at local level
\end{tabular}

\section{Presentation of Four Cases}

In this section, we present the four cases - each with experiences thus far as well as expected outcome.

\section{Case No. 1 at the Macro-Level: The TVET PPP Working Group}

Representation: Our first case to present in connection with a discussion on governance and power-sharing in TVET is the formation of a three-partite TVET PPP Working Group (PPP WG), which Dakchyata established in July 2018. The three parties are MoEST, CTEVT and private sector representatives (central level employer associations, with focus on three crucial sectors of the economy: Agriculture, Construction and Tourism, Dakchyata's 3 focal sectors). The representation between the public and private sector is 50-50\%. Very recently, the PPP WG membership was widened: this meant the inclusion of representation from Ministry of Finance, Ministry of Labour, Employment and Social Security, Ministry of Industry, Commerce and Supplies and National Planning Commission, which all have stakes in TVET. To uphold parity, an equal number of new members from the private sector have been nominated as members.

Objective: The PPP WG will support the strengthening and practical implementation of Nepal's TVET policy through a set of effective policy reforms, built 


\section{$110 \mid$ E. Winther-Schmidt \& R. B. Shrestha}

upon sound initiatives piloted within agriculture, construction and tourism. A major element of the PPP WG will be the establishment and testing of Public-Private Partnership (PPP) models that Dakchyata has constructed (please see below, particularly in Case 4). These will promote participation or shared ownership of the TVET system, support the sustainable development and delivery of an effective TVET system and form a partnership between the supply and demand sides of the labour market. Lessons learned from pilot PPP grant projects will be fed back to the policymakers to explore possibilities of scaling-up and replicating some of the successful PPP models and incorporate such lessons in TVET policies. In this way, the PPP WG will strengthen and implement more effectively a TVET policy responsive to labour market needs. This will be achieved through interventions that bring together those that demand and supply skills within the three economic sectors and through PPPs that enable the piloting of innovative approaches to ensuring the right balance between the responsiveness and appropriate governance of skills. The objective will be achieved by interventions related to supporting the Government's role in TVET and capacity building to enhance the development and implementation of relevant policies, monitoring, and quality assurance. At the same time, these pilots will lead to clarification of the roles that private sector can play in TVET, both in deciding on training contents and in providing hands-on/practical experiences for trainees, to strengthen the relevance and ensure jobs.

Experiences so far: One of the key commitments of the PPP WG is to work together on drafting a Policy Guiding Document (PGD) for TVET PPP in Nepal, united under the common aim of making TVET provision more market-oriented and demanddriven. An outline framework ('skeleton') of the PGD has been formulated and agreed already and the PPP WG meets regularly to discuss the key aspects of TVET, as identified in this framework. Thematic presentations designed to support the WG to elaborate on specific areas under the PGD have been well received, with WG-members agreeing on specific topics and a time-bound action plan through to 2020. An example: The latest WG meeting focused on the mutual benefits of stronger private sector involvement in TVET, emphasizing the advantages both for Government and for the 
private sector itself. Participation and buy-in in the PPP WG are strong from all quarters, both from the public and the private sector.

Expected outcome: The PPP WG represents sharing of governance and powersharing of TVET on the highest level of policy-making and decision-making of TVET in Nepal. The PGD - testing on practical experience on what works and what does not work in TVET in Nepal - will be a catalogue of ideas for Government and the relevant private sectors on how to go about reforming TVET in Nepal in such ways, where new ways of governance and power-sharing can be identified, hopefully leading to increased efficiency and effectiveness in TVET. Further to this, a group of key decision-makers, close to or within the central circles of political power and decision-making pertinent to TVET will get to know each other, will together define what the main issues are in TVET from the point of view of public and private sector and hopefully also learn how to produce lasting outputs and outcomes in TVET in Nepal.

\section{Case No. 2 at the Macro-Level: National Level Labour Market Prioritisation}

While the above TVET PPP WG initiative is by now fully functional and producing results, this second case is still in the making. Dakchyata will provide direct grants to one or several national level employer associations (either general or sector-specific, in Agriculture, Construction and/or Tourism), putting in place mechanism(s) that have the objective of prioritizing and streamlining positions, needs, and points of view of employers within TVET, so to say enabling employers and their organisations to speak with one voice. This has the following background: A scoping study on employer needs with regard to present status and labour market prioritisation was undertaken by Dakchyata in the spring of 2019 to map out the needs of employers and their associations for information about supply and demand of qualifications and skills on the labour market. The findings of the study show that while employers and their representative associations make it clear that they do need up-to-date information on a range of labour market issues, they clearly mention that they are not yet in a position to put in place a mechanism or system that could gather, analyse and disseminate this critically important information, having neither the insights nor the resources to do so. Dakchyata is, therefore, looking at the possibility of establishing a labour market 


\section{2 | E. Winther-Schmidt \& R. B. Shrestha}

secretariat, either within or outside of employer associations - with this decision ultimately being driven by the needs and requirements of the employers themselves.

Experiences so far: Consultative meetings have been conducted in FNCCI, FNCSI, $\mathrm{CNI}$ and HAN and an initiation strategy is currently being developed. A fully-fledged proposal for support in establishing such a labour market secretariat will hopefully be in place before the end of 2019.

Expected outcome: GoN has recently announced that it is willing to restart the establishment of a Labour Market Information System (LMIS), however, with focus on labour and skills supply only, not on the demand side. The above-mentioned scoping study revealed that employers are in fact very keen to see such a system up and running, but employers are presently not in a position to produce the data showing the coordinated demand by employers for qualifications and skills in the labour market. Grant support from Dakchyata to establish a labour market secretariat will enable this data/information production. A primary task of the secretariat will be to collect, prioritise and feed into the LMIS the demands of employers for TVET skills, for new entrants as well as for up-skilling the existing labour force. Once the LMIS is updated, it will be available for all parties in the country: employers, employees, training institutions, students, - and of course Government with its many actors. Needless to say, when such collaboration and prioritisation between public and private sector in LMIS is established, where the partners work together to establish mechanisms where supply and demand for labour, qualifications and skills are balanced and gaps are addressed, this is TVET power-sharing in a very concrete and tangible form.

\section{Case No. 3 at the Meso-Level: Enhancing Employer Engagement in Selected CTEVT Schools}

This third case works mainly at the meso level, with focus on nine different CTEVT institutions, covering all the seven Provinces of Nepal. The main objective of Dakchyata grant given to CTEVT is to establish a systematic way, through which the TVET schools, all operating at the provincial level can proactively reach out to and involve private sector employers in as many school activities as possible. Out of the 45 CTEVT schools, nine have been selected - all of which focus on the three focal sectors Journal of Education and Research, Vol. 10, No. 1, 2020 
of Dakchyata, i.e. agriculture, construction and tourism. In order to identify the most suitable schools, Dakchyata and CTEVT together developed a comprehensive assessment framework. The scope of the framework comprises four key areas for investigation: partnerships; student support; approaches to pedagogy and professionalism; and leadership and governance. These four thematic areas provide guidance to the selected schools to improve the quality of training delivery and placing employers at the centre of skills development. These areas also subsequently provided the framework for the development of activities with the schools and CTEVT centrally, with information gathered during the assessment forming a clear baseline for measuring change through implementation. In addition, of course finding modalities, for CTEVT central level to support all its schools in involving employers, for the sake of covering their needs for human resources and to ensure employability and employment, in the same go.

Experiences so far: This case is still under development. Some months back, assessments were conducted jointly by CTEVT and Dakchyata in all nine schools from across the three focal sectors and covering all seven Provinces of Nepal. The assessment took into consideration a variety of different funding models, ultimately recommending that funds are channelled to the 9 selected schools via CTEVT central level in order to strengthen institutional capacity and oversight mechanisms both centrally and locally, ensuring the sustainability of the proposed activities beyond the life of the grant. Clearly, the nine involved schools will most directly benefit from the Dakchyata grant. But central level CTEVT also will learn how to support all their schools in terms of outreach to employers, exercised on a provincial level of implementation.

Expected outcome: It is expected that the largest TVET provider in the country: The Government-run CTEVT through the grant will develop and find ways to proactively involve employers in as many aspects of TVET school life as possible. We hope to see the schools catering for sector-specific needs of employers in the Province, in which the CTEVT School is situated. Schools will be able to assess local needs for qualifications and skills and deliver these, in their courses offered, in arranging for onthe-job training, where trainees can get hands-on experience and where the world of 


\section{$114 \mid$ E. Winther-Schmidt \& R. B. Shrestha}

work becomes real and tangible for the students, in providing career guidance and in follow-up, assisting both employers and employees to find one another. We aim for a win-win PPP situation, where employers get trainees with the right skills, young people secure employment after training has ended and both central level and provincial level CTEVT will know how to ensure relevance and sustainability in delivery of qualifications and skills, which can be replicated in all the other TVET institutions in Nepal. In the other hand, the tools and equipment used by the schools could be also available for the provincial and local level industries as well as communities to optimum utilization as well as technology transfer. Success and quality in TVET in this context will fully depend on the ability of the CTEVT schools to enter lasting and trustworthy partnership relations with local private sector partners.

\section{Case No. 4 at the Micro-Level: PPP Training Pilots}

Dakchyata has initiated a grant scheme, through which a string of institutions, working in TVET at the local level, will be supported in forming PPP, again within the three focal sectors. The objective could perhaps best be illustrated through an example: a privately operated TVET training institutions will enter a PPP with one or several private companies, where the partners will collaborate to ensure that training of trainees is provided in areas of need as defined by employers and in ways that the employers are proactively participating in designing, to ensure relevance and later employment, once the training is completed. In the same vein, employer organisations like associations, chamber of commerce etc. are encouraged to take the lead in this, meaning that they identify training needs and then find one or several partners, e.g. TVET training institutions to collaborate with, to meet their needs for human resources. Such PPpartnerships build on comparative advantages: employers know best which skills are needed by the new or existing workforce, while TVET institutions know best how to teach such skills. This is the essence of PPP in TVET.

Experiences so far: Dakchyata published a call for proposal around a year ago and has since then received more than 200 proposals. 35 potential lead applicant organisations were found to have met the basic eligibility criteria. All were invited to participate in an intensive capacity-building workshop in Kathmandu in December

Journal of Education and Research, Vol. 10, No. 1, 2020 
2018, designed to increase understanding of the principles of PPP and introduce participants to a variety of employer engagement models across the PPP spectrum, to support the development of more innovative and relevant technical proposals. Such a model could be the well-known apprenticeship model, where the student alternates between learning in school or in a work-place. Or a model where an employer trains the student in its own facility, supported by professional trainers from a TVET school. Or where employers arrange an outlet, in which students both learn and earn in the same site, carrying out real production of for instance a service like in a hotel or restaurant. All applicants could choose from PPP models provided by Dakchyata - or develop their own model! All 35 invited applicants subsequently submitted full proposals; eligibility assessments and qualitative evaluation then took place, ultimately identifying the top 15 proposals for further development. Proposal development experts were then deployed to the field to provide targeted inputs to shortlisted applicants to strengthen and finalise proposals. It has been a long and complicated process, but we expect to enter into a contract with the identified parties in October 2019.

Expected outcome: The outcome so far - in terms of geographic outreach indicates that all seven Provinces of Nepal will be covered, with representation from each of the three focal sectors. Many new and innovative approached have been proposed and it really increases the possibility that some, if not all of the proposals will yield valuable and tangible experiences for Nepal to learn from. Dakchyata will closely monitor developments within all the proposals, once they move towards implementation, to capture the important lessons learned. Focus is on finding new ways to involve employers in e.g. curriculum development in TVET and in assessing, which of the models seem particularly promising in ensuring that students - once their training is completed - actually manage to find employment. Dakchyata will turn all these findings into a catalogue of ideas of what works and what does not work in TVET, awaiting renewal or reform drives, where all these matters are looked into. Copying experiences from elsewhere can be quite problematic - however, if you want to build your renewal or reform on indigenously acquired experiences about what actually works, it is, of course, a must to have access to such first-hand experiences, obtained from the Nepalese context and scene. 


\section{$116 \mid$ E. Winther-Schmidt \& R. B. Shrestha}

\section{Discussion of Findings and Conclusions}

As far as we know, the TVET system of Nepal is not on the verge of entering into the grand reform phase. The existing TVET Policy 2012 still stands and except for adjusting that policy to the constitutional changes of 2015 , i.e. that the new roles of political and administrative players at the federal, provincial and local levels need to be incorporated, the TVET Policy and system remains formally unchanged. As we have argued earlier, conditions under which TVET operate are however always changing and in flux, since they are so closely connected to ever-changing market conditions for production, which in turn dictates the qualifications and skills that labour needs to have. So, while the TVET system, its governance and power-sharing modalities of TVET may presently not undergo any formal changes, TVET still undergoes subtle adjustments and transformations, to some extent both trying to cope with the existing situation and anticipating reforms to come. The Project we work in (i.e., Dakchyata) is operating in that context, where its activities are clarifying the existing way of operation of TVET in Nepal and also demonstrating ways forward for TVET, paying special attention to highlighting the advantages for the TVET system, if the role and influence of employers in TVET governance and power-sharing were strengthened. Keywords in this respect were multi-level interventions, focusing not only on one level of governance, but taking a multi-level approach, in which interventions at the macro, meso and micro levels are tried out simultaneously. Another keyword is that of a public-private partnership modality (PPP). If governance and power-sharing take place through a PPpartnership mode, we believe that partners are allowed to "bring to the table" those insights and expertise, in which they have comparative advantages. It may be neither conducive nor practical that each TVET institution develops its own curriculum or quality standards. Transferability and transparency could not work under those circumstances and these areas are better left with the Government. Having this said, the private sector needs to communicate its need for human resources much more strongly and clearly, not through any one-off desk exercise, but by becoming an active participating partner in everyday life of TVET on all levels. We have called this the broad cross-social country dialogue and broad-based buy-in by all stakeholders that 
need to happen. We hope and think that this approach has become clear in our presentation of the four cases in the above, which are aiming for just that.

Allow us to end our paper through bringing forward some reflections on the relationship between the four cases we have presented as well as on their mutual interconnectivity: The "red thread" in all the 4 cases is the PPP - the public-private partnership modality that runs through them all, in various ways. They all revolve around finding the most efficient and effective ways for the public and private sectors to govern TVET and to share power over TVET in collaborative and flexible ways, building on clear realisation of mutual benefit and not on dictate that needs enforcement to be adhered to by the parties involved. The four cases are clearly interrelated, but also distinct. They operate on a multi-level basis, not covering all levels, but providing examples for illustration purposes from macro- meso- and microlevel operations as well as providing lessons to be learned. However, only the TVET PPP Working Group is operating very close to the political level, where decisions about present and future TVET developments are made. For this very reason, Dakchyata will, of course, present and discuss the various learnings as described in the various cases (Cases 2, 3 and 4) in particular detail with the members of the TVET PPP WG. These lessons learned will be analysed thoroughly and will all be well reflected in the Policy Guiding Document (PGD) that will be officially handed over by the WG to GoN before the Project ends in 2021. We hope that the PGD will inspire GoN to undertake reforms of TVET, in particular, to find ways to strengthen the demand-side of TVET through strengthening the voice of employers and ensure that TVET as a system and as a line of education and training enjoys full support from Government and private sector alike. In our opinion, when done in this way, i.e. that experiences are based on evidence of what works and what does not work in TVET in Nepal, chances are much higher for success through upscale than by copying experiences, which may work well in other countries and under different circumstances. When building on evidence acquired and documented in Nepal, we believe that the widening of governance and power-sharing in TVET is moving down a promising track, pointing towards relevance, quality and sustainability of TVET provisions. It not only paves the way for reform, it also 


\section{8 | E. Winther-Schmidt \& R. B. Shrestha}

highlights the need for reform of systems and ways that a well-functioning and futureoriented TVET system for Nepal should be aiming for.

\section{Notes}

${ }^{1}$ Details of the Project can be found here: https://www.dakchyata-nepal.org/

${ }^{2}$ We both work in the Dakchyata Project - however, this does not imply that we are bound to put forward official views of the Project, since we participate in this Seminar in our personal capacities. Please be aware that we may therefore in this paper express opinions that do not necessarily comply with the British Council or EU views.

${ }^{3}$ The report of the High-Level Commission on Education, which was handed over by the Chairman to the Prime Minister in January 2019 has a Chapter (Chapter 7, pp. 124-151) dedicated to TVET. However, the Government has not yet published the Report and besides, high-level government officials have indicated recently that presently, GoN has no plans to redraft any Law on TVET, except for those changes that follows from federalization, i.e. the spelling out of the existing law on the 3 tiers of government as per the Constitution of 2015.

${ }^{4}$ While companies scream for skills, many young Nepali citizens choose to try their luck in the Gulf or elsewhere. This mismatch-paradox is well captured by Mr. Pawan Sharda of the Sharda Group of Industries in an interview of him in the Kathmandu Post on 10th June 2019 (Bajracharya, 2019).

\section{References}

Asian Development Bank. (2016). Policy priorities for a more responsive technical and vocational education and training system in Cambodia (ADB Briefs No. 73). https://www.adb.org/sites/default/files/publication/217341/cambodia-tvet.pdf

Bajracharya, S. (2019, June 10). Pawan Sharda: Nepal needs more technical expertise. The Kathmandu Post. https://kathmandupost.com/interviews/2019/06/09/pawansharda-nepal-needs-more-technical-expertise

European Training Foundation. (2013). Good multi-level governance for vocational education and training. https://bit.ly/3cGdnAh

Global Development Research Center. (n.d.). Understanding the concept of governance. http://www.gdrc.org/u-gov/governance-understand.html

Ho, R. (2018, July). Baseline study of the Dakchyata TVET practical partnership project. CTEVT.

Ministry of Education, Science and Technology. (2019). High Level National Education Commission report.

Journal of Education and Research, Vol. 10, No. 1, 2020 
Tamayao, M. J. M. (2014). What is governance?

https://tamayaosbc.wordpress.com/2014/08/21/what-is-governance/

UESCO/ILO. (2018). Taking a whole of government approach to skills development. https://unesdoc.unesco.org/ark:/48223/pf0000265549

\section{To cite this article:}

Winther-Schmidt, E., \& Shrestha, R. B. (2020). Governance and power-sharing in TVET in Nepal: Sharing of practical experiences. Journal of Education and Research, 10(1), 100119. https://doi.org/10.3126/jer.v10i1.31901 